\title{
Changing structures of summertime heatwaves over China during 1961-2017
}

\author{
Ning $\mathrm{AN}^{1}$ \& Zhiyan $\mathrm{ZUO}^{2,3^{*}}$ \\ ${ }^{1}$ State Key Laboratory of Severe Weather, Chinese Academy of Meteorological Sciences, Beijing 100081, China; \\ ${ }^{2}$ Department of Atmospheric and Oceanic Sciences/Institute of Atmospheric Sciences, Fudan University, Shanghai 200438, China; \\ ${ }^{3}$ Collaborative Innovation Center on Forecast and Evaluation of Meteorological Disasters, Nanjing University of Information Science and \\ Technology, Nanjing 210044, China
}

Received November 14, 2020; revised March 3, 2021; accepted April 23, 2021; published online July 20, 2021

\begin{abstract}
Despite the prevalence of artificial separation of daytime and nighttime hot extremes, they may actually co-occur or occur sequentially. Considering their potential lead-lag configuration, this study identified an entire heatwave period as consecutive days with either daytime or nighttime hot extremes and investigated the changes of the prevalence and sequence of daytime and nighttime hot extremes during heatwaves over China from 1961 to 2017 . It was found that the majority ( $82 \%$ ) of heatwaves were compound heatwaves that had both daytime and nighttime hot extremes exceeding the 90th percentile-based thresholds, while only $7 \%(11 \%)$ were purely daytime (nighttime) heatwaves that contained only daytime (nighttime) hot extremes. During the entire periods of compound heatwaves, daytime hot extremes usually occurred one day or a few days before nighttime hot extremes, which was in accordance with the daily variations in radiation and meteorological conditions, such as the increasing surface humidity and cloud cover, and decreasing solar radiation during the entire heatwave periods. From 1961 to 2017 , compound heatwave numbers exhibited the sharpest increase with a statistically significant trend of 0.44 times decade ${ }^{-1}$, in contrast to an insignificant trend of 0.00 times decade $^{-1}$ for purely daytime heatwaves and a significant trend of 0.09 times decade $^{-1}$ for purely nighttime heatwaves. Within the compound heatwave periods, hot nights were starting earlier and ending later, and numbers of concurrent daytime-nighttime hot extremes increased significantly at 0.20 days decade ${ }^{-1}$. In particular, urban area were not only subject to increasingly more frequent and longer compound heatwaves, but also to more occurrences of concurrent daytime-nighttime hot extremes with more serious impact. This study provides instructions for researchers to customize and select appropriate heatwave indices.
\end{abstract}

Keywords Heatwaves, Daytime-nighttime coupling, Urbanization, Meteorological conditions

Citation: An N, Zuo Z. 2021. Changing structures of summertime heatwaves over China during 1961-2017. Science China Earth Sciences, 64(8): 1242-1253, https://doi.org/10.1007/s11430-020-9776-3

\section{Introduction}

Observed changes in temperature extremes reflect the pronounced global warming in recent decades (Alexander et al., 2006). Since the mid-20th century, both maximum and minimum temperature extremes have warmed over most land areas (IPCC, 2013) and did not pause during the so-

\footnotetext{
* Corresponding author (email: zuozhy@fudan.edu.cn)
}

called global warming hiatus period of 1998-2012 (Seneviratne et al., 2014). In the meantime, heatwaves, which are commonly recognized as a spell of consecutive extreme warm days, have shown increasing trends in their frequencies and durations worldwide (IPCC, 2013). Heatwaves have become important public concerns, as they take responsibility for the increased levels of weather-related fatalities (WMO, 2013) and pose threats to ecosystem and infrastructure assets, causing tremendous economic loss 
(Klinenberg, 2003; Ciais et al., 2005; Ruthrof et al., 2018; Piao et al., 2019).

Despite a large number of studies, heatwaves still remain events that have not reached a universal definition. When defining heatwaves, many studies impose requirements on a single variable of daily maximum temperature (TX), which usually occurs during daytime, or daily minimum temperature (TN), which usually occurs during nighttime (Bador et al., 2017; You et al., 2017; Oswald, 2018; Ren et al., 2020). There are ongoing studies that require a bivariate threshold of both TX and TN for consecutive days (Kuglitsch et al., 2010; Chen and Li, 2017; Freychet et al., 2017). Some studies further require sequential orders of the TX and TN (Cowan et al., 2014; Oswald and Rood, 2014), for example, Cowan et al. (2014) required a period of extreme TX for at least three consecutive days and extreme $\mathrm{TN}$ on the second and third days. We therefore checked heatwave periods at local meteorological stations in China. Take the city of Beijing as an example (Figure 1), extreme TX and TN can occur separately as purely daytime or nighttime events (Figure 1a, 1b), and they can also occur concurrently and with some sequential orders (Figure 1c, 1d). Hence there is not a one-size-fit-all definition of heatwaves. Factitiously extracting the heatwave periods based on different definitions may come to a different conclusion.

It is more precise and practical to separately quantify the daytime and nighttime temperature extremes when describing heatwave activity (Gershunov et al., 2009). An extremely high daytime temperature can cause heat stroke and can exacerbate the risk of ground-level ozone pollution (Filleul et al., 2006; Gosling et al., 2009; Pu et al., 2017). An extremely high nighttime temperature does not allow people to sufficiently recover from the daytime heat and can cause sleep deprivation and thermoregulation failure (Le Tertre et al., 2006; Gosling et al., 2009; Fischer and Schär, 2010). It is found that hot night temperatures can also reduce the production and quality for crops (Bahuguna et al., 2017). Extreme heat events with a combination of both hot day and hot night may be more detrimental (Nairn and Fawcett, 2013; Wang et al., 2020). The most devastating heatwaves in history were expressed in both daytime and nighttime extreme temperatures, such as the 1995 Chicago heatwave (Kunkel et al., 1996), 2003 European heatwave (Trigo et al., 2005), and 2010 Russian heatwave (Barriopedro et al., 2011).

The relationship between daytime and nighttime extreme temperatures is neither consistent nor contradictory. Physical mechanisms causing daily and nightly high temperatures are related to the land-atmosphere interactions and meteorological conditions. On one hand, the storage of heat in the atmospheric boundary layer during daytime can be preserved in a nocturnal residual layer at night so the abnormal warming during daytime can persist into nighttime (Chen and $\mathrm{Lu}, 2014$; Miralles et al., 2014). Urban surface with (a)

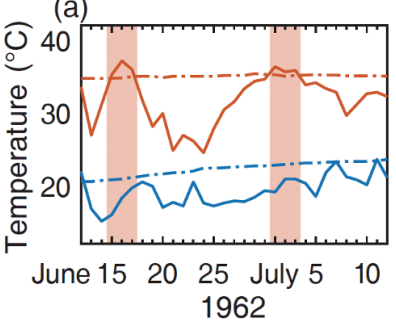

(c)

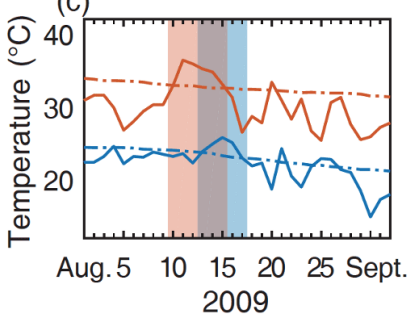

(b)

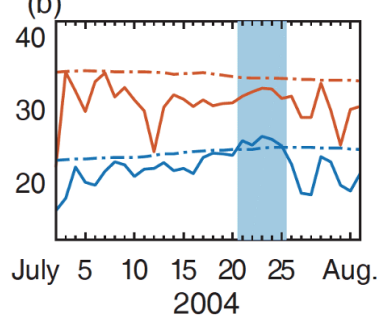

(d)

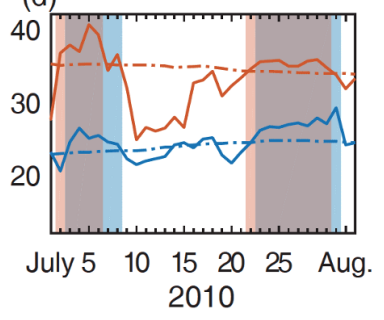

Figure 1 Examples of heatwaves at Beijing station (station code: 54511). Time series of daily maximum temperature (TX, solid red lines), daily minimum temperature (TN, solid blue lines), daily 90th percentile of TX (dash-dot red lines), and daily 90th percentile of TN (dash-dot blue lines) in (a) June 12-July 12, 1962, (b) July 1-Aug. 1, 2004, (c) Aug. 1-Sept. 1, 2009 and (d) July 1-Aug. 1, 2010. Periods of heatwaves (consecutive days with TX or TN exceeding its daily 90th percentile) are highlighted in shaded areas.

materials such as asphalt and concrete, store the energy from daytime solar insolation and slowly release at night as longwave radiation. This phenomenon is referred to as the urban heat island (UHI) effect and can maintain high nighttime temperatures in urban areas compared to rural areas (Oke, 1982). On the other hand, high daytime temperatures are prone to occur under dry conditions with reduced cloudiness (greater downward solar radiation) and downward motion (adiabatic warming), while the nocturnal radiative cooling under cloudless conditions efficiently reduces the nighttime temperature. High nighttime temperatures are prone to occur under moist conditions (greater downward longwave radiation), while the elevated moisture typically results in increased cloudiness and albedo thus suppress daytime temperatures (Gershunov et al., 2009; Bumbaco et al., 2013; Hong et al., 2018). Consequently, daytime and nighttime extremes can occur concurrently and independently.

Instead of analyzing the characteristics and changes of the frequency, duration, and intensity of heatwaves by a given definition, the present research focused more on the changes of heatwave structures, i.e., the configuration of daytime and nighttime temperature extremes during heatwaves. We defined an entire heatwave period as a sequence of days with either hot daytime extremes or hot nighttime extremes. Three main questions were considered: (1) Has the prevalence of daytime and nighttime extremes during heatwaves changed in the period 1961-2017 over China? (2) During heatwaves when both daytime extremes and nighttime extremes ap- 
peared, were daytime extremes more likely to co-occur with, lead or lag behind nighttime extremes?(3) How urbanization and meteorological conditions impacted on the structures of heatwaves?

\section{Data and methods}

This study focused on heatwaves in summertime (June-JulyAugust, JJA). We used observational datasets of daily 2-m air temperature (including TX and $\mathrm{TN}$ ), daily mean low cloud cover (LCC), total cloud cover (TCC), solar radiation $\left(R_{\mathrm{s}}\right)$ and 6-hourly (0200, 0800, 1400 and 2000 Beijing time) air temperature, surface pressure, and relative humidity record at approximately 2400 stations. The 6-hourly data were used to compute the daily mean specific humidity $(q)$. All the data were obtained from the National Meteorological Information Center (NMIC) at the China Meteorological Administration. These are the latest comprehensive observational data from the NMIC and have been through rigorous supervision and quality control (Cao et al., 2016), including correction of suspect and erroneous data; outlier detection; and checking consistencies (internal, temporal and spatial).

Despite the quality control procedure mentioned above, the datasets have not corrected inhomogeneities from nonclimatic factors, e.g., site moves, automated instrument replacement, and observational practices. According to Cao et al. (2016), the major change points of the temperature dataset were from site moves. Therefore, several other criteria were applied in selecting the stations as suggested by Chen and $\mathrm{Li}$ (2017): (1) Retain the stations that have site moves within a 20-km horizontal distance and a 50-m change of elevation in 1961-2017; (2) retain the stations that have sufficient TX and TN observations (less than 5\% missing observations, i.e., 4 days) during JJA for every year during the 57-year period from 1961-2017; (3) retain the stations that have sufficient daily LCC, TCC, $R_{\mathrm{s}}$, and $q$ information (less than $11 \%$ missing observations, i.e., 10 days) during JJA for at least 50 years. The criterion for TX and TN was stricter than the other variables because heatwave periods were determined based on TX and TN. After these procedures, 1051 of the $\sim 2400$ stations were retained. The selected stations were more densely located in the southeast China, while they were less densely located in the northwest China and the northern edge of the northeast China (Figure 2). There were barely any stations in the Qinghai-Tibet plateau area (southwest China), where the high altitude and sparse population result in heatwave events not being a focus for researchers.

To study the effect of urbanization, we separated the selected 1051 stations into urban and rural based on the satellite nighttime brightness index derived from the Defense

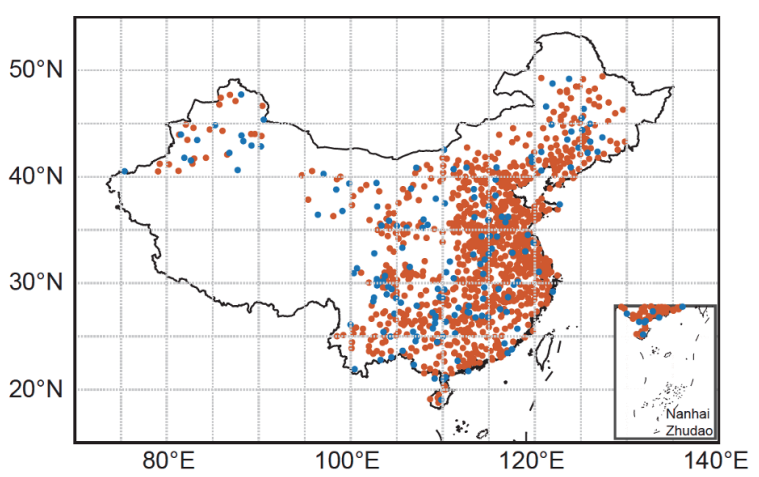

Figure 2 Distributions of the 1051 surface stations (blue dots: 155 rural stations, red dots: 896 urban stations) and $5^{\circ} \times 5^{\circ}$ grid boxes (rectangles).

Meteorological Satellite Program's Operational Linescan System (DMSP/OLS) with compositing period of 2013 (DMSP 2013). The data at each grid (30 arc-second) are recorded as digital numbers ranging from zero to 63 . The threshold to separate urban and rural areas in China generally ranged from 15 to 30 in previous studies (Cao et al., 2009; Tan, 2015; Ye et al., 2018; Wang et al., 2019). In this study, the threshold is set to 25 for the whole country to maintain at least 1 rural station in every $5^{\circ} \times 5^{\circ}$ grid and cover area as much as possible over China. Locations of the separated 155 rural stations and 896 urban stations are shown in Figure 2.

An extreme hot day/night is defined as a day/night when the daily TX/TN exceeds the long-term daily 90th percentile and is referred to as TX90p/TN90p according to the Expert Team on Climate Change Detection and Indices (ETCCDI, see http://etccdi.pacificclimate.org/list_27_indices.shtml). For each day during 1 June to 31 August, the 90th percentile of TX/TN is calculated from the temperature distribution based on a 15-day window centered on that day in the reference period 1961-1990, which has $15 \times 30=450$ samples (Chen and Zhai, 2017). In this study, the entire heatwave period is referred to as consecutive calendar days with either TX90p or TN90p for more than 3 days, for the fact that TX90p and TN90p may not occur exactly on the same dates (Figure 1c, 1d). The duration of a heatwave refers to the total number of days in the entire heatwave period.

Three types of heatwaves are then defined: (1) A purely daytime heatwave: an event that contains only TX90p. (2) A purely nighttime heatwave: an event that contains only TN90p. (3) A compound heatwave: an event that contains both TX90p and TN90p in the period.

In addition, from the view of epidemiology, hot days followed by hot night are more damaging to human health than hot days followed by cool nights because human cannot get sufficient recovery from daytime heat at nighttime (Murage et al., 2017). Accordingly, three types of extreme hot days are defined (Chen and Zhai, 2017): (1) An independent hot day (only daytime hot): a day when TX exceeds the 90th 
percentile in the daytime, while TN does not exceed the 90th percentile in the following night. (2) An independent hot night (only nighttime hot): a day when TX does not exceed the 90th percentile in the daytime, while in the following night TN exceeds the 90th percentile. (3) A concurrent daytime-nighttime hot extreme (both daytime and nighttime hot): a day when TX exceeds the 90th percentile in the daytime and TN exceeds the 90th percentile in following night.

It is obviously that purely daytime heatwaves contain only independent hot days and purely nighttime heatwaves contain only independent hot nights. Therefore, this study primarily analyzed the numbers of these three types of extreme hot days in compound heatwaves.

Other variables, such as $R_{\mathrm{s}}, \mathrm{LCC}$, TCC, and $q$, were used to explain the influence of radiation and meteorological conditions. The $R_{\mathrm{s}}$ dataset is derived from sunshine duration observations based on a hybrid model developed by Yang et al. (2001). According to NMIC, the sunshine-duration-derived $R_{\mathrm{S}}$ has a mean absolute error of $0.0117 \mathrm{MJ} \mathrm{m}^{-2} \mathrm{~d}^{-1}$ and a root mean squared error of $2.44 \mathrm{MJ} \mathrm{m}^{-2} \mathrm{~d}^{-1}$ compared to observations (Liu and Ren, 2016). It was used because $R_{\mathrm{S}}$ observations over China were spatially sparse and suffer from inhomogeneity issues due to instrument replacement and sensitivity drift (He et al., 2018). The observations of LCC and TCC were based on visual cloud reports following the WMO codes (WMO, 1974). They were used because there was no other substitute of cloud cover observation for the study period, and these data had been used to explain long-term climatological variations (Xue et al., 2019). $\mathrm{Hu}-$ man-observed cloud cover in China gradually stopped after 2013 when automated stations were implemented. Therefore, analyses using LCC and TCC were processed before 2013.
For each calendar day from 1 June to 31 August, we calculated the daily anomalies for all variables such as the TX, TN, $q, \mathrm{LCC}$, TCC, and $R_{\mathrm{s}}$ referenced to the average of the same calendar days in the period 1961-1990. To reduce the impacts of spatial heterogeneity, for a specific variable, the national average was calculated as follows: first, the values of all the stations in each $5^{\circ} \times 5^{\circ}$ grid box were averaged. Then, the national mean was calculated by the area-weighted average of all the 36 valid grid boxes. Nation means for urban and rural areas were calculated separately based on the urban and rural stations in the $5^{\circ} \times 5^{\circ}$ grid boxes. The leastsquares method was applied to fit the linear trend, and the two tailed t-test was used to test the significance of the regression equation for simulating the time series. Statistical significance was set at the 0.05 level.

\section{Results}

\subsection{Features and trends of three types of heatwaves}

Figure 3 displays the mean summertime numbers and durations of the three types of heatwaves. It is obviously that compound heatwaves prevailed over purely daytime and nighttime heatwaves in both numbers and durations. On average, there were 2.2 times compound heatwaves in JJA over China, which account for $82 \%$ of the total number of all three types, while only 0.2 times purely daytime heatwaves and 0.3 times purely nighttime heatwaves occurred in summer, which account for $7 \%$ and $11 \%$ of the total numbers, respectively. The mean duration for compound heatwaves over China was 4.8 days, while the durations of purely daytime and nighttime heatwaves were both 3.5 days. These results suggest that the majority of heatwaves have expres- (a) Purely daytime heat waves

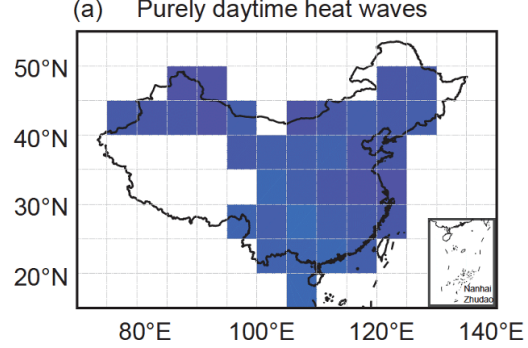

(d)

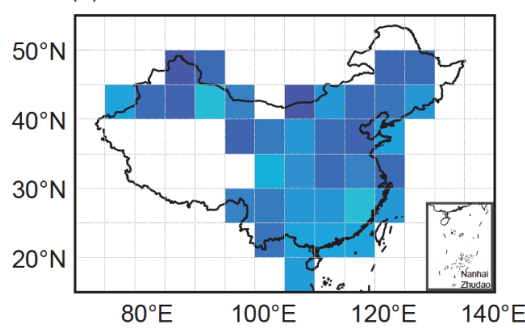

(b) Purely nighttime heat waves

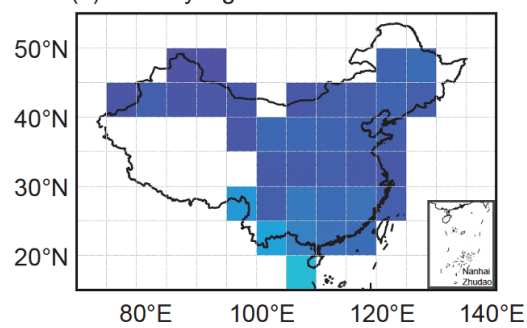

(e)

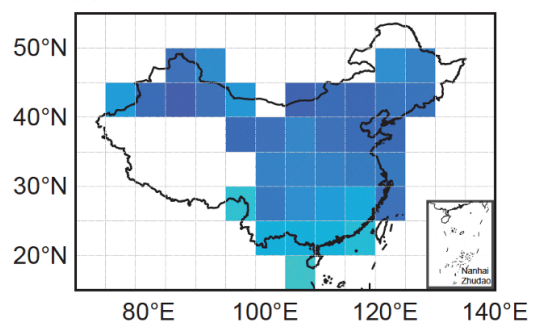

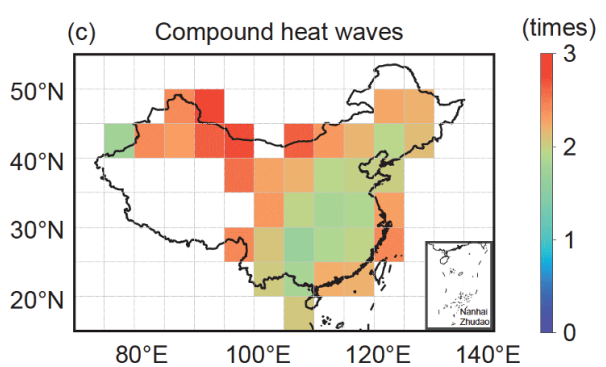

(f)

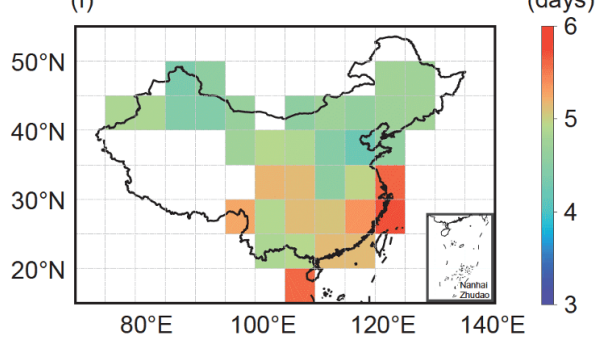

Figure 3 The mean summertime (June-July-August, JJA) numbers of (a) purely daytime heatwaves, (b) purely nighttime heatwaves, and (c) compound heatwaves and the mean summertime durations of (d) purely daytime heatwaves, (e) purely nighttime heatwaves, and (f) compound heatwaves over China during 1961-2017. 
sions in both high daytime and nighttime temperatures, while heatwaves that contain only high daytime or nighttime temperatures are not likely to occur in nature, which may due to that the storage of heat can preserve from day to night in the atmospheric boundary layer. Besides, the relative shorter durations suggest purely daytime and nighttime heatwaves are not as influential as compound heatwaves.

From 1961 to 2017, there was no significant trend $(0.00$ times decade ${ }^{-1}$ ) in the number of purely daytime heatwaves for the whole country though some regions showed significantly increasing or decreasing trends in China (Figure 4a). Purely nighttime heatwaves increased significantly in almost all regions with a trend of 0.09 times decade $^{-1}$ for the whole country (Figure 4b). The numbers of compound heatwaves exhibited the sharpest increase of 0.44 times decade $^{-1}$ and most places experienced significantly increasing trends over China (Figure 4c). Urban and rural areas had opposite trends in the numbers of purely daytime heatwaves, though both were statistically insignificant (Figure 4d). The reason that urban areas had a decreasing trend may be that the UHI effect is generally more pronounced at night, thus urban areas are less likely to experience heatwaves without high nighttime temperatures. Urban areas had a slightly higher trends $\left(0.09\right.$ times decade $\left.{ }^{-1}\right)$ than rural areas $(0.08$ times decade $\left.{ }^{-1}\right)$ in the number of purely nighttime heatwaves (Figure 4e). The differences in the trends of compound heatwave numbers between urban and rural areas were much larger, where urban areas increased significantly at 0.46 times decade ${ }^{-1}$ and rural areas increased significantly at 0.35 times decade ${ }^{-1}$ (Figure 4f).

In terms of heatwave durations (Figure 5a-5c), purely daytime heatwaves also had an overall insignificant trend ( 0.00 days decade ${ }^{-1}$ ), while purely nighttime heatwaves increased significantly at 0.09 days decade ${ }^{-1}$, and compound heatwaves increased more remarkably across the country with a significantly increasing trend of 0.31 days decade $^{-1}$. Urban and rural areas had opposite and insignificant trends in the durations of purely daytime heatwaves (Figure $5 \mathrm{~d}$ ). As shown in Figure 5e, the duration of purely nighttime heatwaves was shorter but increased faster in urban areas (0.09 days decade $\left.{ }^{-1}\right)$ than rural areas $\left(0.07\right.$ days decade $\left.^{-1}\right)$. Urban areas also showed a significantly increasing trend $(0.31$ days decade $\left.^{-1}\right)$ higher than rural areas $\left(0.27\right.$ days decade $\left.{ }^{-1}\right)$ in the duration of compound heatwaves (Figure $5 \mathrm{f}$ ). The above analysis reveals that compound heatwaves with expressions in both high daytime and nighttime temperature were the prominent type of heatwaves and experienced the most rapid increases in both numbers and durations in 1961-2017. In the $1960 \mathrm{~s}$, on average, there were 1.5 times of compound heatwaves over China, while in the $2010 \mathrm{~s}$, there were 3.4 times of compound heatwaves, and numbers were much higher in urban areas (3.5 times) than rural areas (3.0 times). Consequently, more attention is paid to compound heatwaves in the later part of this article.

\subsection{Structures of compound heatwaves}

In this part, we analyzed the sequence of daytime and nighttime extremes during compound heatwaves. As shown in Figure 1c, 1d, TX90p and TN90p might not happen on the same days during heatwaves. Statistical analysis of the lag days between the first TX90p and TN90p during the entire

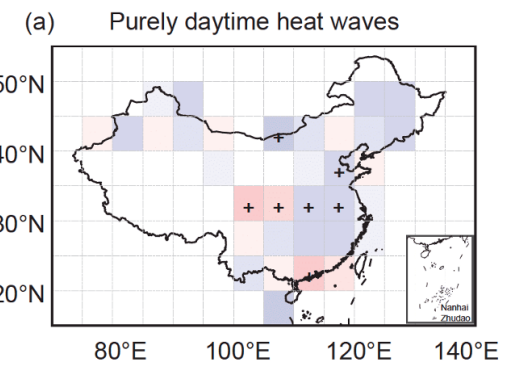

(b) Purely nighttime heat waves

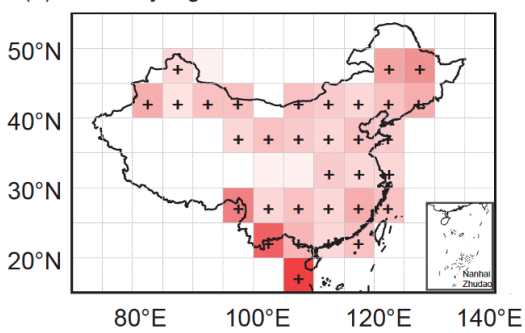

(c) Compound heat waves

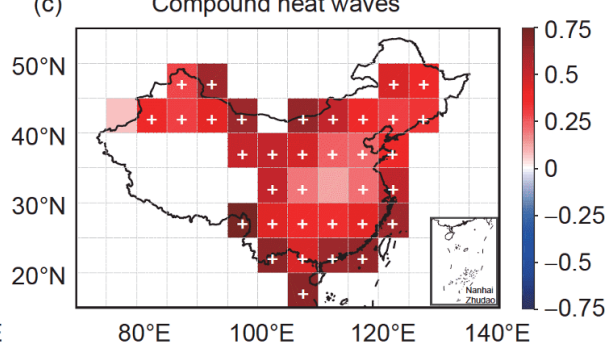

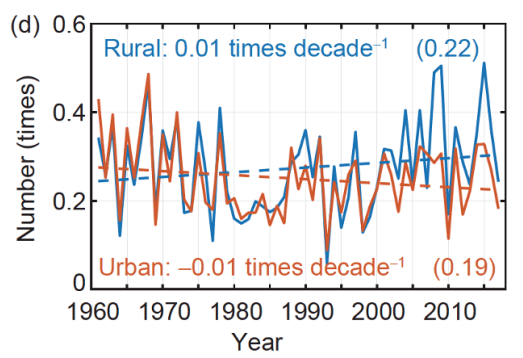
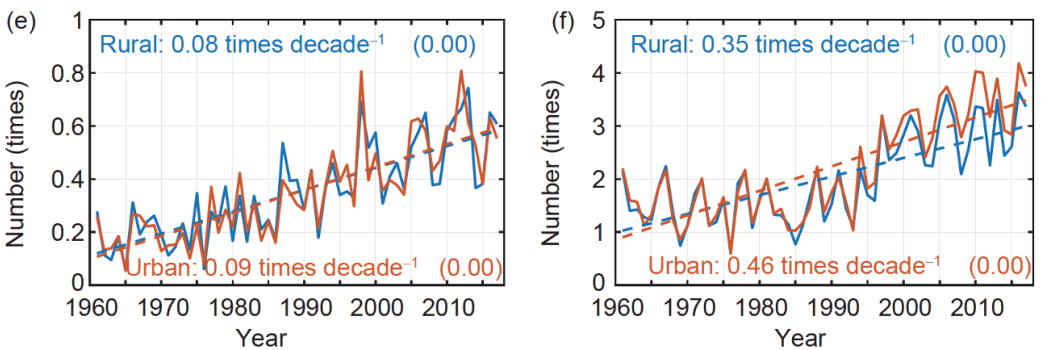

Figure 4 Spatial patterns of decadal trends in the numbers of (a) purely daytime heatwaves, (b) purely nighttime heatwaves, and (c) compound heatwaves and time series of the numbers of (d) purely daytime heatwaves, (e) purely nighttime heatwaves, and (f) compound heatwaves in urban (red) and rural (blue) areas over China in 1961-2017. Symbol ' + ' in (a)-(c) indicates that the trend of a $5^{\circ} \times 5^{\circ}$ grid has passed the two tailed Student's $t$ test at the $95 \%$ confidence level. Texts in (d)-(f) are the trends with the corresponding statistical significance listed in parentheses. 

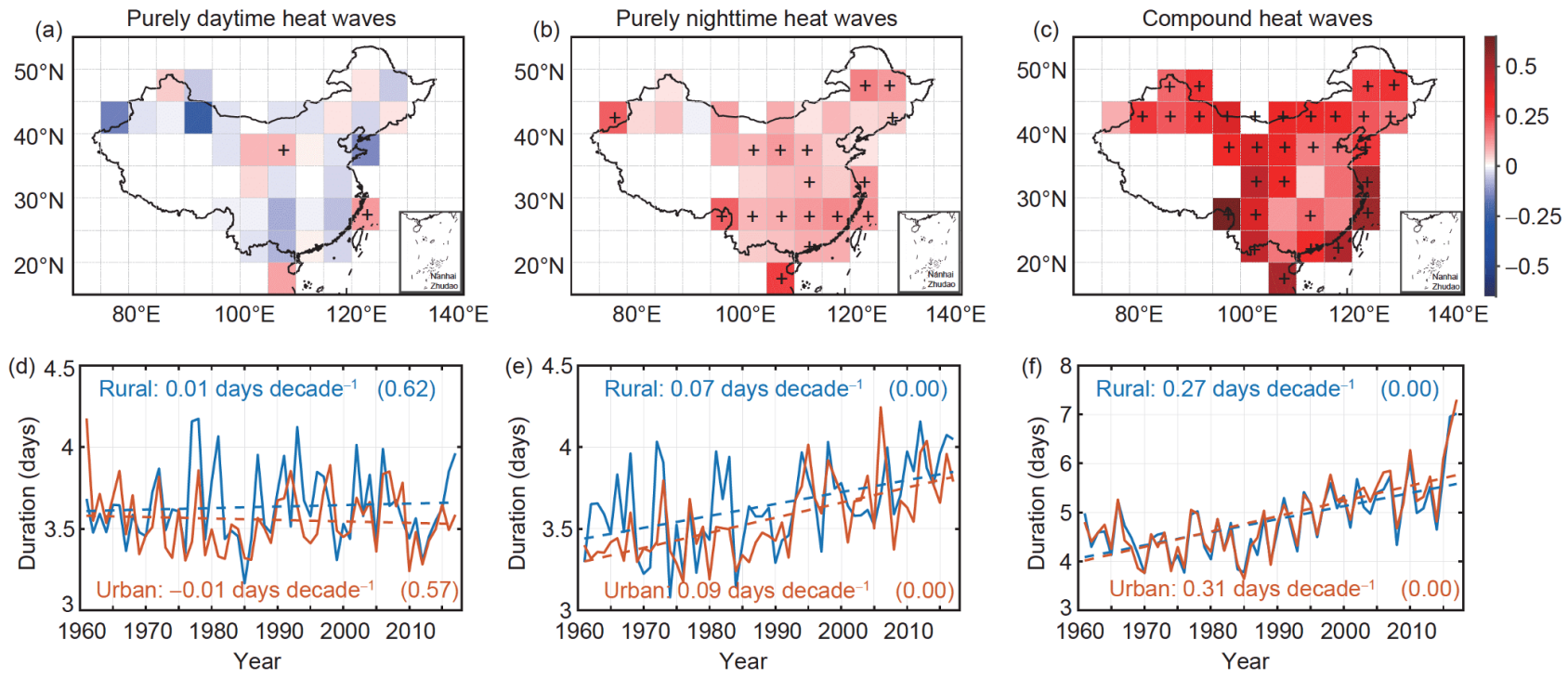

Figure 5 Spatial patterns of decadal trends in the durations of (a) purely daytime heatwaves, (b) purely nighttime heatwaves, and (c) compound heatwaves and time series of the durations of (d) purely daytime heatwaves, (e) purely nighttime heatwaves, and (f) compound heatwaves in urban (red) and rural (blue) areas over China in 1961-2017. Symbol ' + ' in (a)-(c) indicates that the trend of a $5^{\circ} \times 5^{\circ}$ grid has passed the two tailed Student's $t$ test at the $95 \%$ confidence level. Texts in (d)-(f) are the trends with the corresponding statistical significance listed in parentheses.

heatwave periods, calculated as the calendar day of the first TX90p minus the calendar day of the first TN90p, are presented in Figure 6a, 6c. Statistical analysis of the lag days between the last TX90p and TN90p during the entire heatwave periods are presented in Figure 6b, 6d. Figure 6a, 6b display the spatial patterns of the mean lag days between TX90p and TN90p during the entire period of compound heatwaves. In general, TN90p lagged behind TX90p over the whole country except for the southernmost $5^{\circ} \times 5^{\circ}$ grid boxes. Some areas in the eastern China also showed that the first TN90p did not lag behind the first TX90p (Figure 6a). TN90p lagged behind TX90p for nearly two days in some areas in the northwest China. The lag time between TX90p and TN90p were larger in the northwest China than in the southeast China.

Figure $6 \mathrm{c}$ shows the frequency distributions of the lag days between the first TX90p and first TN90p in urban and rural areas. As shown, the frequency of TX90p beginning before TN90p (56\%) was higher than the frequency of TX90p beginning after TN90p (26\%). The frequency was highest when the value of lag day is -1 , which accounted for $27 \%$. Possible reason may be that heat accumulated during daytime can preserve into nighttime through boundary layer processes, causing a high frequency of concurrent TX90p and TN90p. For the lag days between the last TX90p and last TN90p (Figure 6d), the frequency of TX90p ending before TN90p (56\%) was also higher than the frequency of TX90p ending after TN90p (18\%) and the frequency was highest (35\%) when TN90p lagged behind TX90p for one calendar day.

The frequency distributions in urban and rural areas were generally similar but with some small distinctions. For the first TX90p and first TN90p (Figure 6c), the frequencies were slightly higher in urban areas than in rural areas when the value of lag days were greater than zero, while for the last TX90p and last TN90p (Figure 6d), the frequencies were slightly higher in urban areas than in rural areas when the value of lag days were smaller than zero, which indicates that urban areas more frequently experienced earlier started and later ended TN90ps than rural areas. This is reasonable since urban areas typically have higher nighttime temperatures. However, the frequency distributions (Figure 6c, 6d) show that there were relatively higher frequencies when TN90p lagged behind TX90p for even more than three days, which cannot be explained by UHI effect or boundary layer processes.

Evolutions of TX, TN, $q$, LCC, TCC, and $R_{\mathrm{s}}$ anomalies during the entire heatwave periods of compound heatwaves are illustrated in Figure 7. The value of each variable was averaged by heatwaves with same durations. It is shown that during the entire heatwave periods, TX anomalies increased in the earlier stages and decreased in the later stages, while $\mathrm{TN}$ anomalies continuously increased and maintained at high values in the later stages (Figure 7a, 7b). These can be explained by the variations in meteorological and radiation conditions, such as the $q$, LCC, TCC and $R_{\mathrm{s}}$ (Figure $7 \mathrm{c}-7 \mathrm{f}$ ). The relatively lower cloud covers in the earlier stages of the entire heatwave periods allowed more $R_{\mathrm{s}}$ and thus increased TX. As the cloud covers increased, $R_{\mathrm{s}}$ decreased and TX declined in the later stages (Figure $7 \mathrm{~d}-7 \mathrm{f}$ ). The increased cloud cover and near-surface atmospheric water vapor (represented as the $q$ in Figure 7c) strengthened the downward 

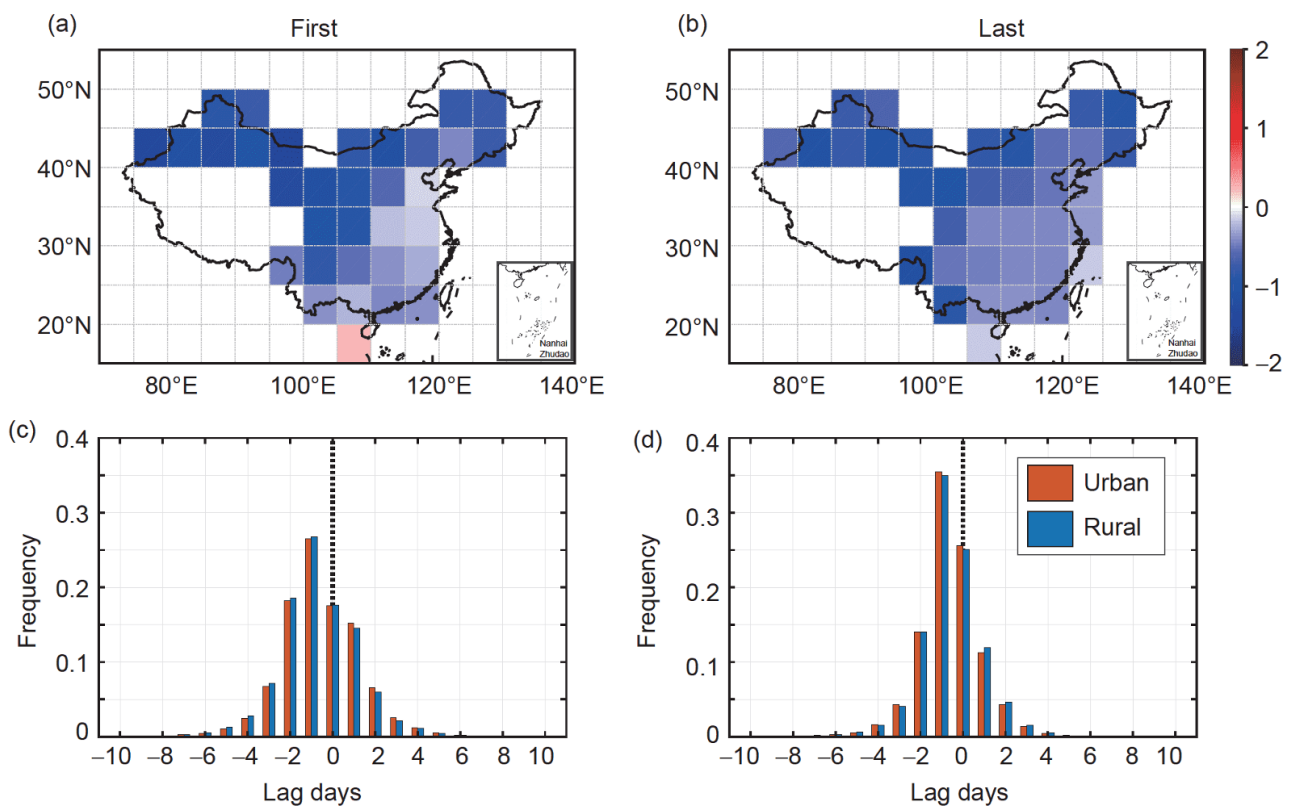

Figure 6 Spatial patterns ((a), (b)) and frequency distributions ((c), (d)) of the lag days between TX90p and TN90p (TX90p-TN90p) during the entire period of compound heatwaves. (a), (c) The statistics of the lag days between the first TX90p and first TN90p during the entire period of compound heatwaves. (b), (d) Same as (a) and (c) but for the last TX90p and the last TN90p during the entire period of compound heatwaves.
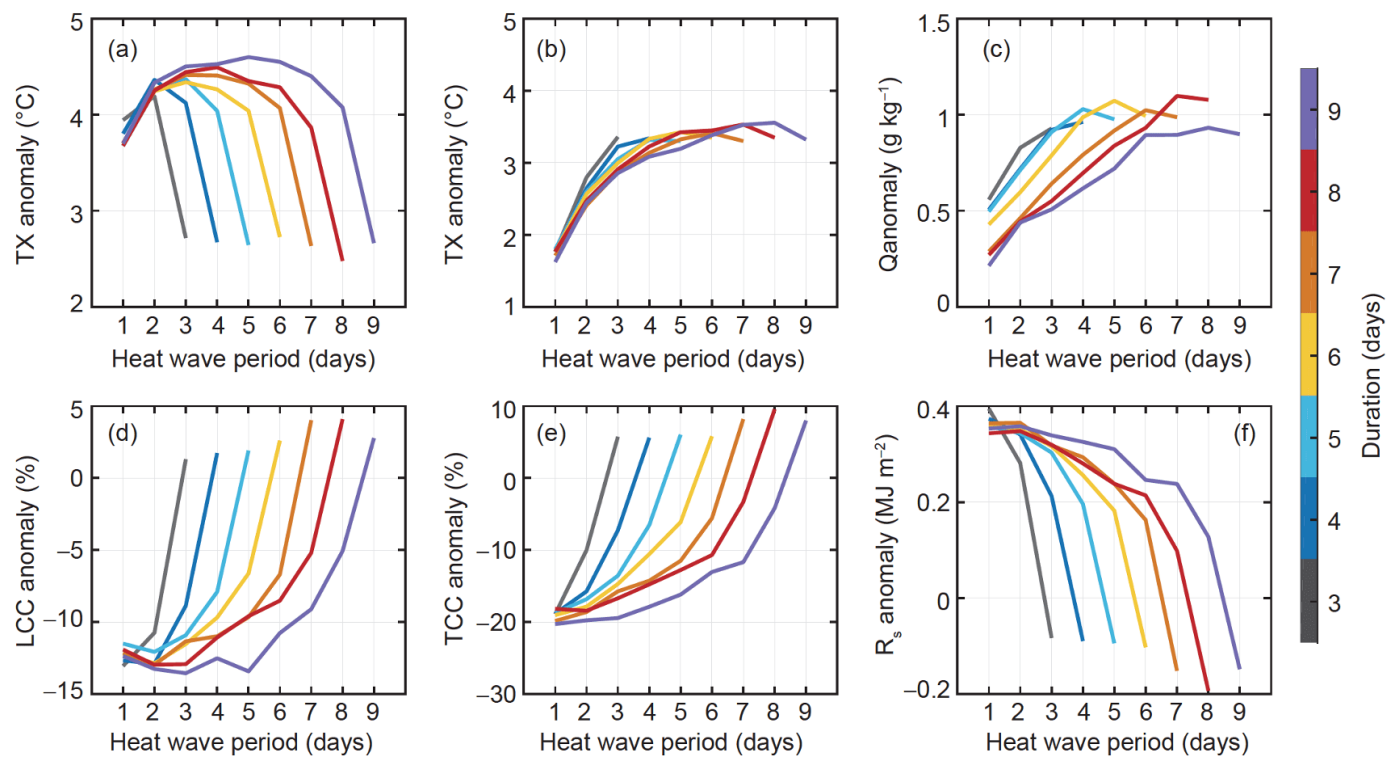

Figure 7 Mean daily variations in (a) daily maximum temperature (TX) anomaly, (b) daily minimum temperature (TN) anomaly, (c) specific humidity ( $q$ ) anomaly, (d) low cloud cover (LCC) anomaly, (e) total cloud cover (TCC) anomaly, and (f) Solar radiation $\left(R_{\mathrm{s}}\right)$ anomaly in each calendar day during the entire compound heatwave periods of different durations (colors) from 3 days to 9 days in 1961-2013 over China.

longwave radiation, thus increasing $\mathrm{TN}$ in the later stages. Consequently, TN90ps can occur behind TX90ps for a few days, such as the example shown in Figure 1c. Lags between TX90p and TN90p were larger in northwest China, which may be because that the surface air humidity conditions and cloud cover are lower in the northwest China than in the southeast China (Dai, 2006; Jin et al., 2009), so that the effects of water vapor and cloud on longwave radiation are not strong in the earlier stages.
We also computed the evolutions of meteorological conditions during the entire heatwave periods when TX90ps lagged behind TN90ps (Figure 8). On average, only 18\% of the cases had both the first TX90p and the last TX90p occurring behind the corresponding TN90ps. There is greater variability in the daily variations shown in Figure 8, which may due to the relative smaller data samples. Nevertheless, it is obviously that the variables in Figure 8 have opposite changes compared to Figure 7. The $q$, LCC, and TCC de- 

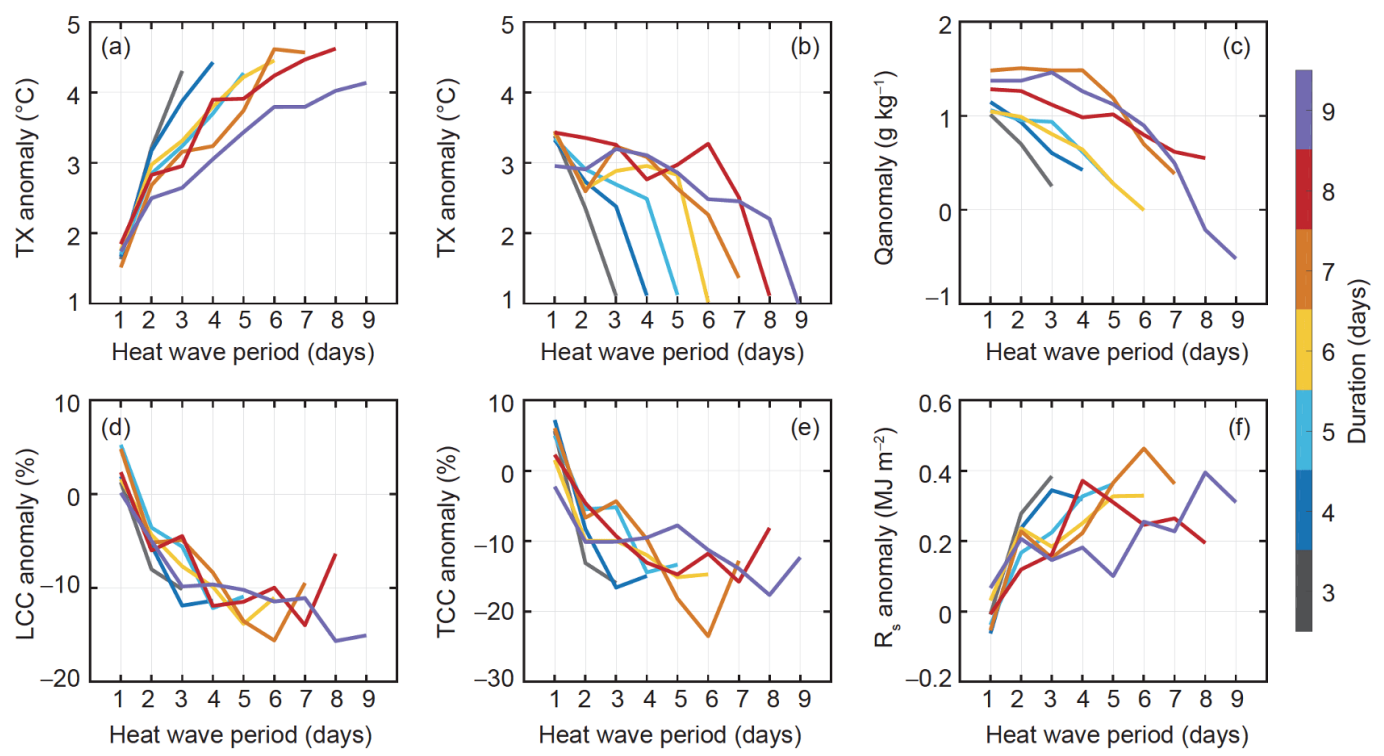

Figure 8 Same as Figure 7 but for compound heatwaves when TX lag behind TN.

creased and $R_{\mathrm{s}}$ increased during the entire heatwave periods, thus TX was higher in the later stages and TN was higher in the earlier stages. The above results suggest that meteorological conditions and radiation observably regulate the appearance of TX90p and TN90p during heatwave periods. It should be noted that each particular heatwave event may have distinct variations based on the air mass changes and cloud cover conditions, which differ from the average states shown in Figure 7.

\subsection{Changes in the structure of compound heatwaves}

Trends in the lag days between the first TX90p and first TN90p from 1961 to 2017 had an opposite direction compared to those in the lag days between the last TX90p and last TN90p (Figure 9). Most of the areas over China had positive trends in the lag days between the first TX90p and first TN90p except some areas in the southwest (Figure 9a). On average, the trends were larger in urban areas $(0.08$ days decade $\left.^{-1}\right)$ than in rural areas $\left(0.05\right.$ days decade $\left.{ }^{-1}\right)$ and both were significant at the 0.05 level (Figure 9c). However, most of the areas over China had significantly negative trends in the lag days between the last TX90p and last TN90p, with a small difference between urban $\left(-0.08\right.$ days decade $\left.{ }^{-1}\right)$ and rural areas $\left(-0.09\right.$ days decade $\left.^{-1}\right)$. These results indicate that hot nights were occurring earlier and there were longer tails of hot nights during the entire heatwave periods, implying that heatwaves were more prevalent at nighttime.

Changes in the numbers of independent hot days, independent hot nights, and concurrent daytime-nighttime hot extremes within the compound heatwave periods are shown in Figure 10. On average, there were 1.4 independent hot days, 1.6 independent hot nights, and 1.9 concurrent day- time-nighttime hot extremes within compound heatwave durations. Spatial differences also appeared (Figure 10a10c), such as numbers of independent hot nights were larger in the southeast China than in the northwest China. During the study period, independent hot days within compound heatwave periods became fewer in most parts of China (Figure 10d). The trend is -0.04 days decade ${ }^{-1}(p=0.03)$ for the whole country, but for rural areas the trend is insignificant (Figure 10g). Numbers of independent hot nights within compound heatwave periods increased throughout the country with a significant trend of 0.15 days decade ${ }^{-1}$, and the difference between urban and rural areas ( 0.15 days decade $^{-1}$ and 0.14 days decade ${ }^{-1}$, respectively) was relatively small (Figure 10e, 10h). Most areas over China experienced significantly increasing trend in the numbers of concurrent daytime-nighttime hot extremes with a country mean of 0.20 days decade ${ }^{-1}$ and the trend is much higher in urban areas $\left(0.20\right.$ days decade $\left.^{-1}\right)$ than rural areas $\left(0.14\right.$ days decade $\left.^{-1}\right)$. On average, there were 1.6 days of concurrent daytimenighttime hot extremes in 1960s while there were 2.5 days in 2010s. These results are consistent with the trends of lag days shown in Figure 9, implying that nighttime heat became more prevalent during heatwaves, so independent hot days have been increasingly replaced by independent hot nights and concurrent daytime-nighttime hot extremes.

\section{Discussion}

In this study, the results in urban and rural areas were calculated by the stations in $5^{\circ} \times 5^{\circ}$ grid boxes. This relatively rough resolution provides opportunity to include more stations and cover larger area. To test if the results are de- 

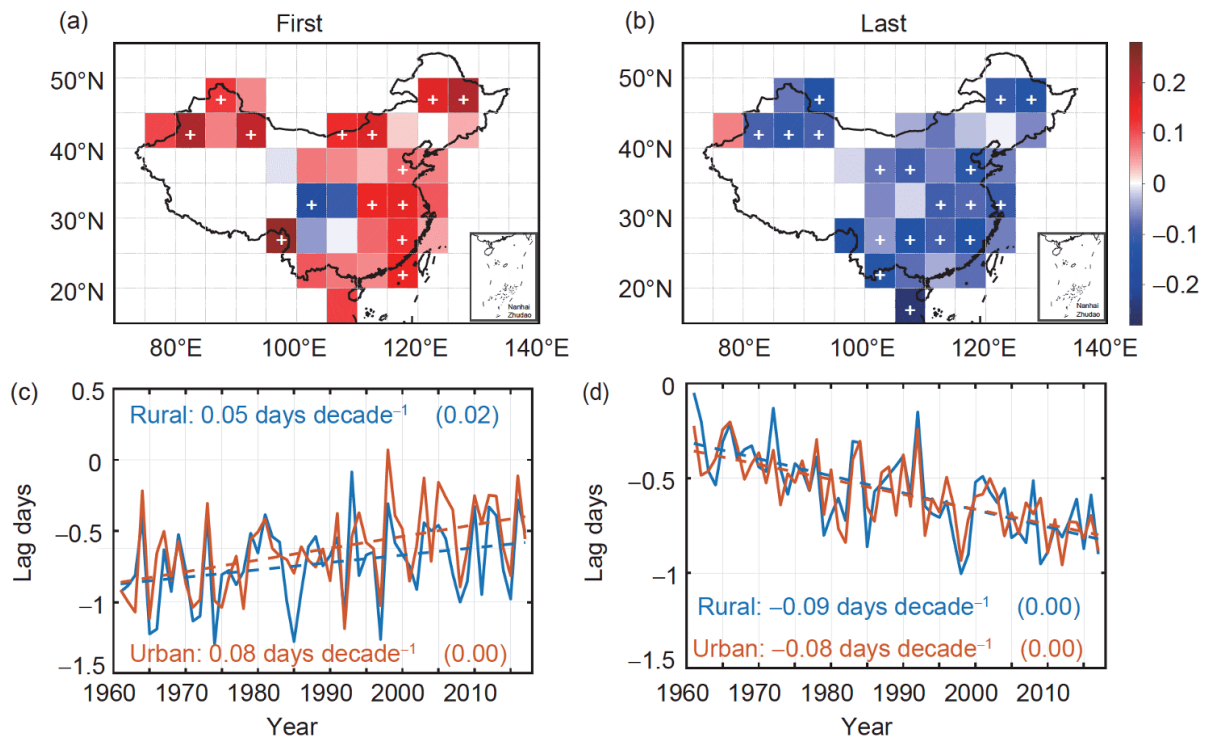

Figure 9 Spatial patterns of decadal trends ((a), (b)) and time series ((c), (d)) of the lag days between TX90p and TN90p (TX90p-TN90p) during the entire period of compound heatwaves. (a), (c) refer to the lag days between the first TX90p and first TN90p during the entire period of compound heatwaves. (b), (d) are the same as (a) and (c) but for the last TX90p and the last TN90p during the entire period of compound heatwaves. Symbol '+' in ((a), (b)) indicates that the trend of a $5^{\circ} \times 5^{\circ}$ grid has passed the two tailed Student's $t$ test at the $95 \%$ confidence level. Texts in ((c), (d)) are the trends with the corresponding statistical significance listed in parentheses.
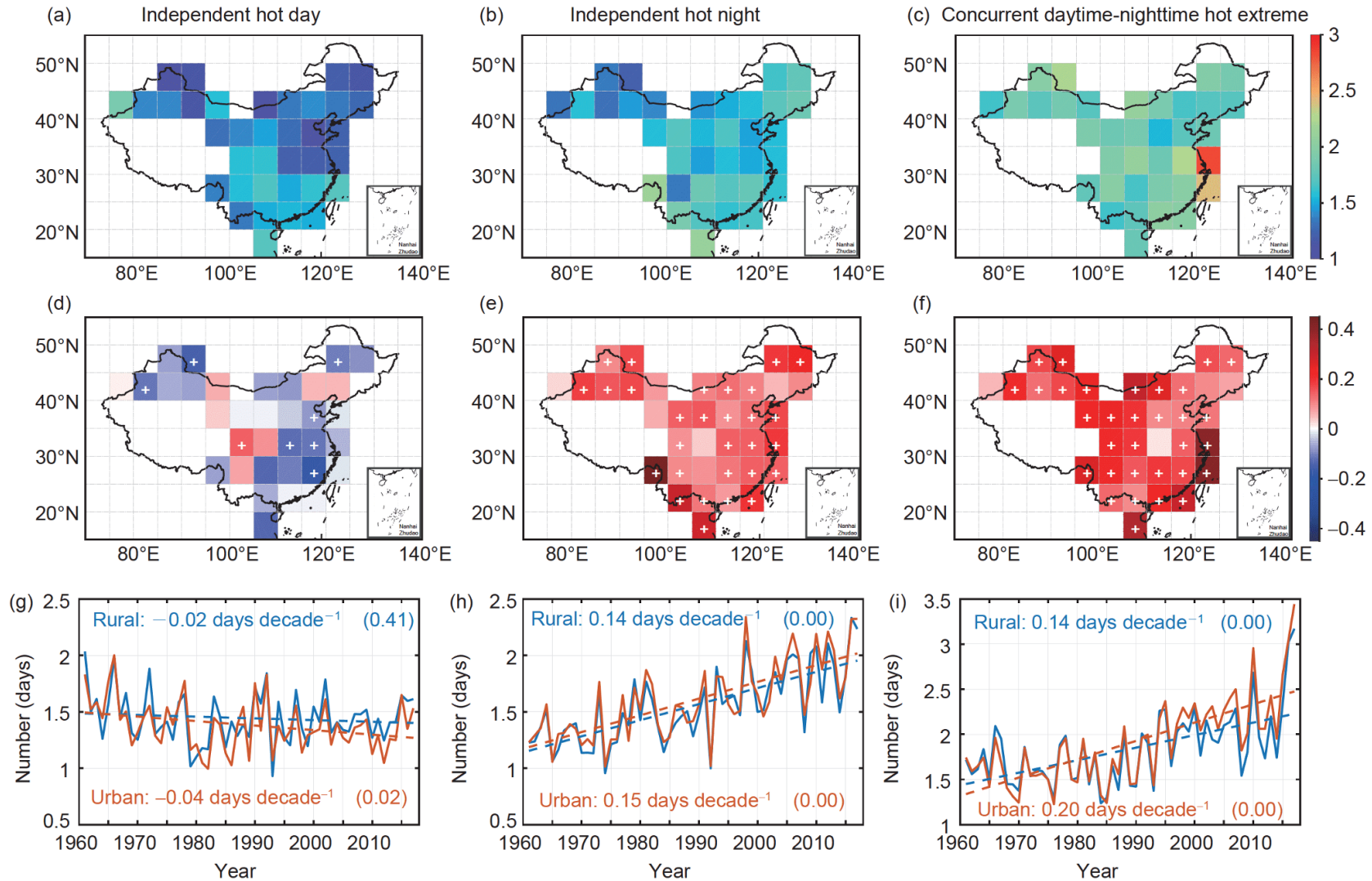

Figure 10 The spatial patterns of mean numbers ((a)-(c)) and decadal trends ((d)-(f)), and time series ((g)-(i)) of the three types of extreme hot days within compound heatwaves: independent hot day (the left column), independent hot night (the middle column), and concurrent daytime-nighttime hot extreme (the right column) over China in 1961-2017. Symbol ' + ' in ((d)-(f)) indicates that the trend of a $5^{\circ} \times 5^{\circ}$ grid has passed the two tailed Student's $t$ test at the $95 \%$ confidence level. Texts in ((g)-(i)) are the trends with the corresponding statistical significance listed in parentheses.

pendent on the classification method, we also carried out sensitivity experiments using finer grid box such as $2.5^{\circ} \times 2.5^{\circ}$ (Appendix Figures S1-S3, https://link.springer. com) and $1^{\circ} \times 1^{\circ}$ grid box (Figures S4-S6). Finer resolutions 
result in less stations meet the criteria (Figures S1 and S4). Although the statistics and trends vary between experiments using different resolutions, the differences are generally small and do not affect the main conclusions (Figures S2, S3, S5 and S6), such as compound heatwaves and purely nighttime heatwaves increased significantly during 1961 to 2017, while purely daytime heatwaves had insignificant trends, and urban areas had much higher trends in the number of compound heatwaves and concurrent daytime-nighttime hot extremes.

The purpose of this study is not to give a standard definition of heatwaves, but to provide a reference for researchers to select or customize heatwave indices and to understand the potential limitations of the selected definition. For example, when using the definitions based on TX, one must notice that apart from the trends in numbers or durations, hot days are more likely to occur accompanied by hot nights, such strengthened coupling between hot days and hot nights may make heatwaves more damaging. Besides, using the definitions based on TX and using the definitions based on TN may extract different periods (e.g., earlier stages and later stages) of a heatwave with different radiation and meteorological conditions. One should be cautious with the potential differences associated with different definitions.

This study showed that radiation and meteorological conditions strongly influenced the occurrence of hot days and hot nights. Cloud cover and surface humidity generally increased through the entire heatwave periods, resulting in hot days occurring ahead of hot nights. A case study suggested that the sources of the increased moisture included both local evaporation and moisture advection (An et al., 2020). Future studies will investigate the relevant mechan-
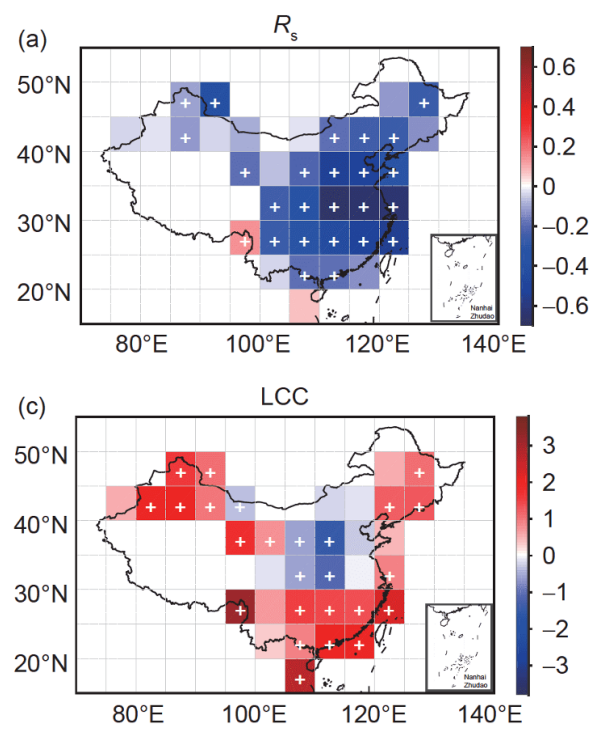

isms involving the roles of land-atmosphere processes and atmospheric circulations. During the study period, $R_{\mathrm{s}}$ decreased significantly over the country (Figure 11a), $q$ increased significantly in the northwest and northeast China (Figure 11b), and LCC increased significantly in most areas except the north China (Figure 11c), where the increasing TCC (Figure 11d) and elevated aerosol concentration from air pollution also contribute to the declining $R_{\mathrm{s}}$ according to Xue et al. (2019). Such overall increased humidity and LCC, and decreased $R_{\mathrm{s}}$ were in favor of more hot nights and suppressed the increase of hot days.

A shortcoming of this study is that although spatial patterns were provided, this study primarily concentrated on features of the whole country. Further studies will pay attention to the changes of heatwave structures at different regions and possible causes for the changes. Another shortcoming is that we did not quantify how much heat can preserve into nighttime from daytime through boundary layer processes. Giving the same capacity factor of preserving energy through boundary layer processes, if daytime temperature increases, nighttime temperature is also expected to increase, thus causing an increase of concurrent daytime and nighttime hot extremes. We calculated the mean TX anomaly and TN anomaly during the entire heatwave periods for heatwaves with different numbers of concurrent daytimenighttime hot extremes (Figure 12). It is clear that heatwaves with higher temperature anomalies, namely higher intensity, come up to more concurrent daytime-nighttime hot extremes in their structure. However, such boundary processes are not yet well understood and require further analysis based on observational experiment and land-atmosphere model simulations.
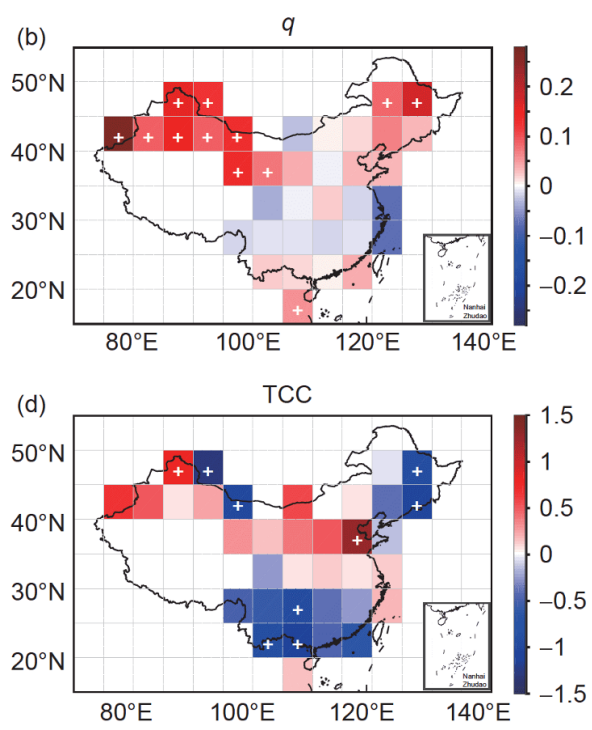

Figure 11 Spatial patterns of decadal trends in the summertime (JJA) (a) sunshine duration-based solar radiation $\left(R_{\mathrm{s}}\right)$ anomaly, (b) specific humidity $(q)$ anomaly over China from 1961 to 2017, and (c) low cloud cover (LCC) anomaly and (d) total cloud cover (TCC) anomaly over China from 1961 to 2013 in every $5^{\circ} \times 5^{\circ}$ grid. Symbol ' + ' indicates that the trend of a $5^{\circ} \times 5^{\circ}$ grid has passed the two tailed Student's $t$ test at the $95 \%$ confidence level. 


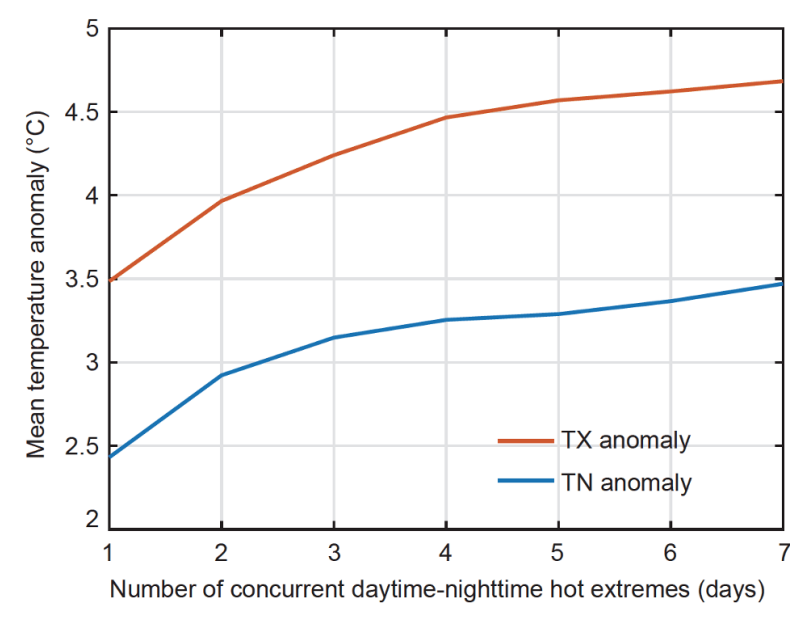

Figure 12 Mean temperature (TX and $\mathrm{TN}$ ) anomalies for the entire heatwave periods with different numbers of concurrent daytime-nighttime hot extremes in 1961-2017 over China.

\section{Conclusions}

Heatwave definitions are widely diverse among existing research literature, which might lead to some confusion in the broader discussion of climate trends. This study, instead of analyzing the climate trends based on a predefined index, but investigates how the configuration of hot days and hot nights changed over China during the past decades. An entire heatwave period was identified as consecutive days with either hot daytime temperature or hot nighttime time temperature. It is shown that compound heatwaves that had expressions in both extremely high daytime temperature and extremely high nighttime temperature were the most prominent type of heatwaves, compared to purely daytime and nighttime heatwaves that contained only one kind of temperature extremes. Radiation and meteorological conditions regulated the appearance of hot days and hot nights during compound heatwaves. Cloud cover and surface humidity generally increased through heatwave periods, thus there were higher frequencies of hot days occurring before hot nights.

In the study periods, heatwaves became more prevalent at nighttime and compound heatwave experienced the sharpest increase in both numbers and durations during 1961 to 2017. Within the compound heatwave periods, hot nights were starting earlier and ending later. Numbers of independent hot days were increasingly replaced by independent hot night and concurrent daytime-nighttime hot extremes. The differences in the trends of independent hot nights between urban and rural areas were generally small, whereas urbanization mostly contributed to compound heatwaves and concurrent daytime-nighttime hot extremes, suggesting that urbanization strengthened the coupling between hot days and hot nights.

This study investigated the changes of structures of heatwaves over China in the past decades. Knowledge of the past characteristics of heatwaves can help predict future changes. With the global temperature continue rising and urbanization accelerating, it can be predicted that compound heatwaves with more concurrent daytime-nighttime hot extremes are bound to increase in the future.

Acknowledgements We would like to thank Yang Chen from Chinese Academy of Meteorological Sciences for his valuable help. Surface meteorological observations were obtained from the Chinese Meteorological Administration (CMA, http://data.cma.cn/en). This work was supported by the National Key R\&D Program (Grant No. 2016YFA0601502) and the National Natural Science Foundation of China (Grant Nos. 41822503 and 41375092).

Open Access This article is licensed under a Creative Commons Attribution 4.0 International License, which permits use, sharing, adaptation, distribution and reproduction in any medium or format, as long as you give appropriate credit to the original author(s) and the source, provide a link to the Creative Commons licence, and indicate if changes were made. The images or other third party material in this article are included in the article's Creative Commons licence, unless indicated otherwise in a credit line to the material. If material is not included in the article's Creative Commons licence and your intended use is not permitted by statutory regulation or exceeds the permitted use, you will need to obtain permission directly from the copyright holder. To view a copy of this licence, visit http://creativecommons.org/licenses/by/4.0/.

\section{References}

An N, Dou J, González-Cruz J E, Bornstein R D, Miao S, Li L. 2020. An observational case study of synergies between an intense heat wave and the urban heat island in Beijing. J Appl Meteorol Climatol, 59: 605-620

Alexander L V, Zhang X, Peterson T C, Caesar J, Gleason B, Klein Tank A M G, Haylock M, Collins D, Trewin B, Rahimzadeh F, Tagipour A, Rupa Kumar K, Revadekar J, Griffiths G, Vincent L, Stephenson D B, Burn J, Aguilar E, Brunet M, Taylor M, New M, Zhai P, Rusticucci M, Vazquez-Aguirre J L. 2006. Global observed changes in daily climate extremes of temperature and precipitation. J Geophys Res, 111: D05109

Bador M, Terray L, Boé J, Somot S, Alias A, Gibelin A L, Dubuisson B. 2017. Future summer mega-heatwave and record-breaking temperatures in a warmer France climate. Environ Res Lett, 12: 074025

Bahuguna R N, Solis C A, Shi W, Jagadish K S V. 2017. Post-flowering night respiration and altered sink activity account for high night temperature-induced grain yield and quality loss in rice (Oryza sativa L.). Physiol Plant, 159: 59-73

Barriopedro D, Fischer E M, Luterbacher J, Trigo R M, García-Herrera R. 2011. The hot summer of 2010: Redrawing the temperature record map of Europe. Science, 332: 220-224

Bumbaco K A, Dello K D, Bond N A. 2013. History of Pacific Northwest heat waves: Synoptic pattern and trends. J Appl Meteorol Climatol, 52: 1618-1631

Cao L, Zhu Y, Tang G, Yuan F, Yan Z. 2016. Climatic warming in China according to a homogenized data set from 2419 stations. Int J Climatol, 36: 4384-4392

Cao X, Chen J, Imura H, Higashi O. 2009. A SVM-based method to extract urban areas from DMSP-OLS and SPOT VGT data. Remote Sens Environ, 113: 2205-2209

Chen R, Lu R. 2014. Dry tropical nights and wet extreme heat in Beijing: Atypical configurations between high temperature and humidity. Mon Weather Rev, 142: 1792-1802

Chen Y, Li Y. 2017. An inter-comparison of three heat wave types in China during 1961-2010: Observed basic features and linear trends. Sci Rep, 7: 45619

Chen Y, Zhai P. 2017. Revisiting summertime hot extremes in China 
during 1961-2015: Overlooked compound extremes and significant changes. Geophys Res Lett, 44: 5096-5103

Ciais P, Reichstein M, Viovy N, Granier A, Ogée J, Allard V, Aubinet M, Buchmann N, Bernhofer C, Carrara A, Chevallier F, De Noblet N, Friend A D, Friedlingstein P, Grünwald T, Heinesch B, Keronen P, Knohl A, Krinner G, Loustau D, Manca G, Matteucci G, Miglietta F, Ourcival J M, Papale D, Pilegaard K, Rambal S, Seufert G, Soussana J F, Sanz M J, Schulze E D, Vesala T, Valentini R. 2005. Europe-wide reduction in primary productivity caused by the heat and drought in 2003. Nature, 437: 529-533

Cowan T, Purich A, Perkins S, Pezza A, Boschat G, Sadler K. 2014. More frequent, longer, and hotter heat waves for Australia in the twenty-first century. J Clim, 27: 5851-5871

Dai A. 2006. Recent climatology, variability, and trends in global surface humidity. J Clim, 19: 3589-3606

DMSP. 2013. Operational linescan system (DMSP/OLS)

Filleul L, Cassadou S, Médina S, Fabres P, Lefranc A, Eilstein D, Le Tertre A, Pascal L, Chardon B, Blanchard M, Declercq C, Jusot J F, Prouvost H, Ledrans M. 2006. The relation between temperature, ozone, and mortality in nine french cities during the heat wave of 2003. Environ Health Perspect, 114: 1344-1347

Fischer E M, Schär C. 2010. Consistent geographical patterns of changes in high-impact European heatwaves. Nat Geosci, 3: 398-403

Freychet N, Tett S, Wang J, Hegerl G. 2017. Summer heat waves over Eastern China: Dynamical processes and trend attribution. Environ Res Lett, 12: 024015

Gershunov A, Cayan D R, Iacobellis S F. 2009. The great 2006 heat wave over California and Nevada: Signal of an increasing trend. J Clim, 22: 6181-6203

Gosling S N, Lowe J A, McGregor G R, Pelling M, Malamud B D. 2009. Associations between elevated atmospheric temperature and human mortality: A critical review of the literature. Clim Change, 92: 299-341

He Y, Wang K, Zhou C, Wild M. 2018. A revisit of global dimming and brightening based on the sunshine duration. Geophys Res Lett, 45: 4281-4289

Hong J S, Yeh S W, Seo K H. 2018. Diagnosing physical mechanisms leading to pure heat waves versus pure tropical nights over the Korean Peninsula. J Geophys Res Atmos, 123: 7149-7160

IPCC. 2013. Climate Change 2013. The physical science basis. In: Stocker T F, Qin D, Plattner G K, Tignor M, Allen S K, Boschung J, Nauels A, Xia Y, Bex V, Midgley P M, eds. Contribution of Working Group I to the Fifth Assessment Report of the Intergovernmental Panel on Climate Change. Cambridge: Cambridge University Press. 1535

Jin X, Wu T, Li L, Shi C. 2009. Cloudiness characteristics over Southeast Asia from satellite FY-2C and their comparison to three other cloud data sets. J Geophys Res, 114: D17207

Klinenberg E. 2003. Review of heat wave: Social autopsy of disaster in Chicago. N Engl J Med, 348: 666-667

Kuglitsch F G, Toreti A, Xoplaki E, Della-Marta P M, Zerefos C S, Türkeş M, Luterbacher J. 2010. Heat wave changes in the eastern Mediterranean since 1960. Geophys Res Lett, 37: L04802

Kunkel K E, Changnon S A, Reinke B C, Arritt R W. 1996. The July 1995 heat wave in the Midwest: A climatic perspective and critical weather factors. Bull Am Meteorol Soc, 77: 1507-1518

Le Tertre A, Lefranc A, Eilstein D, Declercq C, Medina S, Blanchard M, Chardon B, Fabre P, Filleul L, Jusot J F, Pascal L, Prouvost H, Cassadou S, Ledrans M. 2006. Impact of the 2003 heatwave on all-cause mortality in 9 French cities. Epidemiology, 17: 75-79

Liu N, Ren Z. 2016. Data specification on the China national stations' estimated surface total solar radiation dataset V1.0. National Meteorological Information Center

Miralles D G, Teuling A J, van Heerwaarden C C, Vilà-Guerau de Arellano
J. 2014. Mega-heatwave temperatures due to combined soil desiccation and atmospheric heat accumulation. Nat Geosci, 7: 345-349

Murage P, Hajat S, Kovats R S. 2017. Effect of night-time temperatures on cause and age-specific mortality in London. Environ Epidemiol, 1: 1

Nairn J, Fawcett R J. 2013. Defining heatwaves: Heatwave defined as a heat impact event servicing all community and business sectors in Australia. CAWCR Technical Report No. 060

Oke T R. 1982. The energetic basis of the urban heat island. Q J R Meteorol Soc, 108: 1-24

Oswald E M. 2018. An analysis of the prevalence of heat waves in the United States between 1948 and 2015. J Appl Meteorol Climatol, 57: $1535-1549$

Oswald E M, Rood R B. 2014. A trend analysis of the 1930-2010 extreme heat events in the continental United States. J Appl Meteorol Climatol, 53: $565-582$

Piao S, Zhang X, Chen A, Liu Q, Lian X, Wang X, Peng S, Wu X. 2019. The impacts of climate extremes on the terrestrial carbon cycle: A review. Sci China Earth Sci, 62: 1551-1563

Pu X, Wang T J, Huang X, Melas D, Zanis P, Papanastasiou D K, Poupkou A. 2017. Enhanced surface ozone during the heat wave of 2013 in Yangtze River Delta region, China. Sci Total Environ, 603-604: 807816

Ren L, Wang D, An N, Ding S, Yang K, Freychet N, Tett S F B, Dong B, Lott F C. 2020. Anthropogenic influences on the persistent night-time heat wave in summer 2018 over northeast china. Bull Am Meteorol Soc, 101: S83-S88

Ruthrof K X, Breshears D D, Fontaine J B, Froend R H, Matusick G, Kala J, Miller B P, Mitchell P J, Wilson S K, van Keulen M, Enright N J, Law D J, Wernberg T, Hardy G E S J. 2018. Subcontinental heat wave triggers terrestrial and marine, multi-taxa responses. Sci Rep, 8: 13094

Seneviratne S I, Donat M G, Mueller B, Alexander L V. 2014. No pause in the increase of hot temperature extremes. Nat Clim Change, 4: 161-163

Tan M. 2015. Urban growth and rural transition in China based on DMSP/ OLS nighttime light data. Sustainability, 7: 8768-8781

Trigo R M, Garia-Herrera R, Diaz J, Trigo I, Valente M. 2005. How exceptional was the early August 2003 heatwave in France? Geophys Res Lett, 32: L10701

Wang J, Chen Y, Tett S F B, Yan Z, Zhai P, Feng J, Xia J. 2020. Anthropogenically-driven increases in the risks of summertime compound hot extremes. Nat Commun, 11: 528

Wang L, Li W, Wang P, Liu X, Yang F, Qu J J. 2019. Spatiotemporal characterization of the urban sprawl and its impacts on urban island in China with DMSP/OLS and MODIS measurements. Theor Appl Climatol, 138: 293-303

WMO. 1974. Manual on codes. WMO Publ. 306, Vol: 348. Available at https://www.wmo.int/pages/prog/www/WMOCodes/ManualonCodes. html\#Codes, last accessed July 8th, 2019

WMO. 2013. The Global Climate 2001-2010: A decade of climate extremes-Summary report. WMO-No. 1119: 20. Available at http:// library.wmo.int/pmb_ged/wmo_1119_en.pdf, last accessed July 8th, 2019

Xue W, Guo J, Zhang Y, Zhou S, Wang Y, Miao Y, Liu L, Xu H, Li J, Chen D, Liu H. 2019. Declining diurnal temperature range in the North China Plain related to environmental changes. Clim Dyn, 52: 61096119

Yang K, Huang G W, Tamai N. 2001. A hybrid model for estimating global solar radiation. Sol Energy, 70: 13-22

Ye H, Huang Z, Huang L, Lin L, Luo M. 2018. Effects of urbanization on increasing heat risks in South China. Int J Climatol, 38: 5551-5562

You Q, Jiang Z, Kong L, Wu Z, Bao Y, Kang S, Pepin N. 2017. A comparison of heat wave climatologies and trends in China based on multiple definitions. Clim Dyn, 48: 3975-3989 